\title{
ERRATUM
}

\section{Proposal That the Species Vibrio anguillarum Bergman 1909, Vibrio piscium David 1927, and Vibrio ichthyodermis (Wells and ZoBell) Shewan, Hobbs, and Hodgkiss 1960 Be Combined as a Single Species, Vibrio anguillarum}

\author{
MARGARET S. HENDRIE, W. HODGKISS, and J. M. SHEWAN \\ Torry Research Station, Aberdeen, AB9 8DG, Scotland
}

Vol. 21, no. 1, p. 65, column 1, line 8: Change "NCMB $828=$ ATCC $14181=$ strain 4063 from Smith" to read "NCMB 829 = ATCC 14181 = strain 2911 from Smith." 